\title{
RESENHA
}

\section{Filosofia da matéria e história do homem: a eternidade pelos astros de Louis-Auguste Blanqui}

\section{REVIEW}

Philosophy of matter and history of man: the eternity by the stars of Louis-Auguste Blanqui

\author{
Matheus Landau de Carvalho*
}

BLANQUI, Louis-Auguste. A eternidade pelos astros. Tradução de Luciana Persice. Rio de Janeiro: Rocco, 2016. 126p.

\begin{abstract}
A cada minuto, a cada segundo, milhares de direções diferentes se oferecem a esse gênero humano. [...] Quantos desvios, para um lado e para o outro, modificam os indivíduos, a história!
\end{abstract}

Louis-Auguste Blanqui.

Filho de Jean Dominique Blanqui, vice-prefeito de Puget-Théniers, comuna localizada no sudeste da França, Louis-Auguste Blanqui (1805-1881) estudou Direito e Medicina, destacando-se, historicamente, por sua vida política como um militante socialista e republicano, passando cerca de trinta e sete anos preso às suas ideias e ações revolucionárias, iniciadas em 1830, sob forte influência do movimento de Babeuf. Karl H. Marx testemunhará em, O 18 Brumário de Luís Bonaparte, o fracasso da jornada de 15 de maio de 1848, movimento do proletariado para anular a Assembleia Nacional francesa, ao escrever que, "Como se sabe, o 15 de Maio não teve outro resultado senão o de afastar Blanqui e seus camaradas, isto é, os verdadeiros dirigentes do partido proletário da cena pública durante todo o ciclo que estamos considerando" (MARX, 2002, p. 29).

Louis-Auguste Blanqui escreveu, A eternidade pelos astros (L'Éternité par les Astres em francês), na prisão onde foi levado após ser condenado pela sua liderança na Comuna de Paris, em 1871. Ele mesmo registra, na última parte da obra que "O que

\footnotetext{
* Mestre em Ciência da Religião pela Universidade Federal de Juiz de Fora. Membro do Núcleo de Estudos de Religiões e Filosofias da Índia (NERFI) e da Associação Brasileira de História das Religiões (ABHR).
} 
estou escrevendo agora, em uma cela do Fort du Taureau, escrevi e escreverei por toda a eternidade, a uma mesa, com uma pluma, vestindo esses trajes, em circunstâncias, todas, semelhantes. O mesmo vale para todas as pessoas [...]" (BLANQUI, 2016, p. 122). Nesse trecho, ele se enxerga nas mesmas premissas que defende acerca da relação entre o livre-arbítrio humano e a recorrência de certas diretrizes percebidas na natureza do tempo.

Com o objetivo de compreender a condição humana, segundo as categorias de tempo e espaço, consideradas a partir das dimensões da eternidade e do infinito, o pensador francês dialoga ao longo dos oito capítulos de A eternidade pelos astros, com pensadores como o marquês de Laplace (1749-1827), F. W. Herschell (1738-1822) e Dominique Arago (1786-1853). Neste intuito, Blanqui lança mão de (i) fontes químicas - como a tabela periódica -, (ii) físicas - as obras de Laplace - e (iii) literárias - como As Mil e Uma Noites -, além de um (iv) vocabulário técnico baseado em termos especializados da Geografia e da Astronomia - como periélio, eclíptica, nebulosa, afélio, paralaxe e precessão equinocial - na exposição de suas especulações e verificações.

Apesar da dedicação às questões de natureza astronômica e à redação nem sempre acessível a um outsider das ciências exatas ou das ciências naturais, muito devido ao seu vocabulário técnico e específico ao longo, principalmente, dos capítulos intermediários, há uma nítida e recorrente preocupação do autor, através de todo o livro, com a questão da natureza do tempo em si. Se Blanqui, supostamente, corre risco de perder as rédeas de um discurso histórico-filosófico em seus diálogos com Laplace, assim como sobre a origem do universo, é para recuperá-las em um outro nível mais adiante, de modo que, nos capítulos finais, ele consegue unir as duas pontas da obra a partir dos problemas enunciados na parte inicial do livro em torno do tempo, do espaço e do infinito.

No primeiro capítulo, "O universo - O infinito", Blanqui alude à tese de que a infinitude temporal do universo é irrevogável de sua infinitude espacial, e que a matéria, em sua totalidade, não diminui nem aumenta um átomo sequer, apesar de sua perpétua e inexaurível transformação. No segundo capítulo, "O indefinido", o autor destaca a imprescindibilidade da noção de indefinido, assim como das limitações e capacidades da inteligência humana, para a compreensão do infinito. Como bem destaca o francês, 
Pode-se [...] prolongar à vontade o indefinido, sem ultrapassar os limites da inteligência, e sem nem mesmo começar a alcançar o infinito. Sendo cada palavra a indicação das mais assustadoras distâncias, estamos falando de bilhões e bilhões de séculos, uma palavra por segundo, para, finalmente, não exprimir mais que uma insignificância, em se tratando do infinito (BLANQUI, 2016, p. 18).

No terceiro capítulo, “As distâncias prodigiosas das estrelas”, Blanqui dedica-se às breves divagações sobre dimensões e proporções siderais de tamanho, distância e velocidade mantidas entre estrelas e planetas, estabelecendo paralelos de comparação com realidades empíricas da vida cotidiana do ser humano dentro de um universo que "parece se estender como uma imensidão diante de nossos olhos. Entretanto, ele só nos mostra uma parcela muito pequena" (BLANQUI, 2016, p. 19).

No quarto capítulo, "A constituição física dos astros", o autor chama a atenção para o fato de que um horizonte, outrora objeto de especulação da fantasia humana sobre realidades para além do planeta Terra revela, de fato, uma sincronia empírica das leis físico-químicas de um plano geral de toda possibilidade da matéria concreta com uma pluralidade de "corpos simples", isto é, unidades irredutíveis constituintes da tabela periódica. Essas porções concorrem, desigualmente, para a formação de elementos, substâncias e formas de energia passíveis de existência no plano de toda realidade do universo sideral, inclusive, do nosso planeta.

A partir de duas dificuldades presentes na teoria do marquês de Laplace envolvendo a gravitação universal acerca da origem e alta temperatura das nebulosas e da natureza dos cometas, o pensador francês discorre, no quinto capítulo, "Observações sobre a cosmogonia de Laplace - Os cometas", sobre a relação gravitacional entre cometas e planetas, alicerçado nas teorias do próprio Laplace e também de Dominique Arago, assim como no papel do que denomina de luzes zodiacais nas dinâmicas siderais implicadas nas relações entre massa e energia. $\mathrm{O}$ autor, não apenas se preocupa com a definição categórica de termos da astronomia, como também reconhece a dificuldade oferecida pelo cometa na realização desse objetivo, apontando para a identidade de composição físico-química entre nebulosas e cometas - apesar das diferenças concretas e visíveis entre os dois -, tal como para um confronto teórico entre resultados obtidos por meio da espectrometria e das conclusões de Laplace.

Blanqui inicia o sexto capítulo, "A origem dos mundos", discutindo a questão sobre a origem do universo segundo as maneiras pelas quais a gravitação, as nebulosas e os cometas se relacionam entre si. O autor dedica-se, ao longo do capítulo, às reflexões 
sobre a sucessão interminável de várias existências siderais transitórias nos limites das dinâmicas físicas da mecânica celeste, de acordo com as combinações relativas possíveis entre calor, movimento e elementos químicos que compõem a matéria.

No começo do sétimo capítulo, "Análise e síntese do universo", o revolucionário francês discorre sobre a aritmética superlativa das dimensões siderais captadas pela Astronomia, retomando, em seguida, a questão que relaciona a eternidade garantida pelas inúmeras combinações siderais possíveis da matéria entre os elementos químicos que a constituem com a finitude do universo, determinado pelo número limitado dessas mesmas combinações. O autor aponta para as causas físicas da diversidade dos astros, para o modo como a semelhança e a repetição constituem a regra dos mecanismos da matéria, e como a diferença e a variedade expressam, por outro lado, a exceção a essas coordenadas.

O pensador francês refere-se aos problemas acerca da capacidade simbólica que as cifras numéricas possuem de ilustrar as dimensões superlativas de toda a matéria sideral, se considerarmos a dúvida sobre a finitude ou infinitude do universo. $\mathrm{O}$ autor analisa como realidades podem se repetir tantas vezes quanto as combinações de diretrizes da matéria no espaço se fizerem presentes, segundo determinadas configurações de massa, energia e gravitação. Blanqui faz conjecturas sobre variações circunstanciais de realidades materiais possíveis dentro das leis físicas permitidas pelos astros que as originaram, com reflexos, inclusive, nos limites e possibilidades do livre arbítrio humano, principalmente, no que tange às suas dimensões políticas e psicológicas, sem que haja possibilidade para um inusitado absoluto nos princípios que orientam os fatos humanos em si, pois, para o pensador francês, "o Universo inteiro é a reprodução permanente, sem fim, de um material e um pessoal sempre renovado e sempre o mesmo" (BLANQUI, 2016, p. 104).

No oitavo e último capítulo, "Resumo", o autor aborda a maneira pela qual a relação entre o número finito de corpos simples que compõem toda a matéria do universo - isto é, os elementos da tabela periódica -, e o número incalculável de combinações que eles permitem à fecundidade da natureza determina um tempo que se repete infinitamente, no qual todo presente é redundante de si mesmo em uma atualidade eternizada, diluindo, com isso, a concepção de progresso que se estabelece entre o suposto atraso de um passado e os hipotéticos avanços qualitativos de um futuro. Como Blanqui registra, “[...] O Universo se repete sem fim e se agita frenético, mas 
imóvel. A eternidade encena, imperturbável, no infinito, as mesmas representações” (BLANQUI, 2016, p. 126).

É possível ao leitor perceber, ao longo dos capítulos de A eternidade pelos astros, a presença sutil de um linguajar caracteristicamente militante quando questões de natureza sideral são tratadas por Blanqui. Ao discorrer sobre a natureza e os movimentos dos cometas, o revolucionário francês registra que

\begin{abstract}
Não seriam sobretudo eles os cativos suplicantes, acorrentados há séculos às barras de nossa atmosfera e pedindo em vão liberdade ou hospitalidade? Do seu primeiro ao último raio, o Sol intertropical nos mostra esses pálidos ciganos que espiam tão duramente sua visita indiscreta a homens abastados (BLANQUI, 2016, p. 42)
\end{abstract}

No mesmo capítulo, ao abordar as relações gravitacionais entre planetas e cometas, o pensador afirma que "Os cometas, em suas visitas, talvez levem a pensar que são contingentes prisioneiros. [...] Se eles evitam Saturno, é para caírem nas malhas de Júpiter, agente policial do sistema" (BLANQUI, 2016, p. 40).

Interessante observar, em outros trechos do livro, como Blanqui reflete acerca de algumas consequências sociais do contexto histórico industrial no qual viveu enquanto homem do século XIX. Ao tratar de teorias acerca da origem do mundo em voga na época, o socialista francês escreve que

\footnotetext{
A piada comum a essas teorias é a criação, nos espaços imaginários, de uma usina que fabrica calor à vontade para o abastecimento da volatização indefinida de todas as nebulosas e de todas as matérias caóticas possíveis (BLANQUI, 2016, p. 56)
}

Ao abordar as causas da diversidade na constituição dos vários sistemas solares que compõem o espaço sideral, Blanqui também utilizará a palavra "usina" para explicar que "A principal [causa da diversidade] reside nas desigualdades de volume das nebulosas, que levam a desigualdades correspondentes em tamanho e número dos planetas de sua usina" (BLANQUI, 2016, p. 84).

Com efeito, a obra, A eternidade pelos astros, pode ser vista como um reflexo do contexto histórico industrial e tecnológico em que foi elaborada, sintoma do fim de um século XIX que vivia a necessidade de formular respostas claras às questões que ligavam, diretamente, o discurso histórico às reais condições cotidianas de vida dos seres humanos. É possível observar que as ideias e argumentos do pensador francês poderiam ser situados entre um projeto de Teoria da História, ao debruçar-se sobre uma 
análise sistematicamente epistemológica da condição material, empírica, do ser humano, e um projeto de Filosofia da História, preocupado com a questão do "sentido da História" e com o progresso humano no decurso da história, ou com a necessidade de entender a lógica imanente ao desenvolvimento histórico da humanidade.

Blanqui faz, nas palavras do organizador e apresentador da edição, o Prof. Dr. Marco Lucchesi, uma poética do tempo e do espaço a partir de premissas cosmológicas, segundo ideias e representações que se repetem infinitamente sem o alívio proporcionado pelo vigor de qualquer pensamento estético ou trágico e dos seus desdobramentos comportamentais. Ao redigir uma biografia da eternidade no espaço infinito, o pensador francês parece ter levado as exigências científicas de um materialismo histórico às dimensões superlativas, principalmente, ao considerar o livre arbítrio humano nos limites das possibilidades físicas e químicas encerradas por toda a matéria para além de diretrizes sociológicas e políticas, seja no espaço, seja no tempo. 


\section{REFERÊNCIAS}

BLANQUI, Louis-Auguste. A eternidade pelos astros. Tradução de Luciana Persice. Rio de Janeiro: Rocco, 2016.

MARX, Karl Heinrich. O 18 Brumário e Cartas a Kugelmann. Tradução de Leandro Konder e Renato Guimarães. 7. ed. Rio de Janeiro: Paz e Terra, 2002. 